\begin{tabular}{c} 
journal homepage: http://ijiemjournal.uns.ac.rs/ \\
International Journal of Industrial \\
Engineering and Management \\
Volume $11 /$ No $1 /$ March $2020 / 50-60$ \\
\hline
\end{tabular}

\title{
A framework for food traceability: case study - Italian extra-virgin olive oil supply chain
}

\author{
R. Guido, G. Mirabelli, E. Palermo, V. Solina * \\ University of Calabria, Department of Mechanical, Energy and Management Engineering, \\ Rende (Cosenza), Italy
}

\section{A B STRACT}

In recent decades, numerous regulations about food traceability have been promulgated, in order to protect health and safety of final consumer and to prevent fraudulent behaviour. The aim of this paper is to propose a framework for tracking and tracing an extra-virgin olive oil supply chain, located in Calabria, in the South Italy. Starting from the results of a market survey, we propose a traceability model, which increases the perceived value of the product placed on the market, and can be easily reused by small enterprises. We outline some possible future developments, based on the blockchain technology.

\section{ARTICLE INFO}

Article history:

Received September 2, 2019

Revised February 12, 2020

Accepted February 13, 2020

Published online March 3, 2020

\author{
Keywords: \\ Food traceability; \\ Food industry; \\ Olive oil supply chain; \\ Blockchain; \\ Food safety \& quality \\ *Corresponding author: \\ Vittorio Solina \\ vittorio.solina@unical.it
}

\section{Introduction}

Food traceability, in addition to being a precise regulatory provision, is becoming increasingly significant in the variegated world of the trade globalization. Data and information on producer and territorial manufacturing context, reported on each product label, are not sufficient to reassure consumer on authenticity and safe of the product. In fact, after the food scandals of recent years, consumer has become considerably more demanding and wary. Fraud prevention, regulatory compliance, response speed in the event of sanitary emergency are among the most recognized advantages of a traceability system [1].
However, in this context, additional features can be considered: a well-implemented traceability system can give an amount of information about the product, such as to considerably enrich its perceived value by consumer. This increases the brand awareness and has very positive effects on sales.

Referring to the most recent Coop Report, which is the study annually carried out by Coop Italia to analyse the distribution market, it is evident that the choice to propose products, healthy, organic, with Protected Designation of Origin (PDO), allows companies to gain a significant competitive advantage. In particular, the study shows that the food products market is converging towards a clear diversification 
of customers, based on price, quality, innovation, area of origin and health content of food. For example, referring only to the organic products, which more than others need a "traced supply chain" to be protected, in the Italian food expenditure there is a turnover of 1.3 billion euro, which represents the $4 \%$ of the total food turnover. The purchase of organic products has "infected" all the facilities operating in the distribution. In fact, in 2018 almost 10\% of the products present in hypermarkets are organic foods, while there is a greater diffusion in other commercial structures $(+34 \%)$, including food discount stores. The segment of the organic products, even if present for more than 10 years on the Italian table, is still very dynamic with growth rates of almost 15\%. Among the most appreciated organic products are those that are part of the Mediterranean diet and the ingredients most used to prepare typical meals. In fact, the products with the highest growth margins in 2018 are: eggs $(+19 \%)$, extra virgin olive oil $(+14 \%)$, cereals for breakfast $(+7 \%)$ yoghurt $(+5 \%)$ [2].

This paper concerns the extra virgin olive oil supply chain, and in particular the chain constituted by a consortium of Calabrian farmers, who want to differentiate their product through a traceability project. The main objective is to illustrate the framework to guarantee the traceability of extra-virgin olive oil, which was proposed as part of the regional research project named "Olio extra vergined'oliva Digital Id maNagement (ODIN)", funded by the European Union (EU).

This scientific paper is structured as follows: in Section 2 we review the literature, focusing on: the general aspects of food traceability, the main regulations in Europe, and the most important models for tracking and tracing olive oil supply chains. Sections 3 and 4 describe the problem and the proposed framework for solving it, respectively. Section 5 lists preliminary and expected results, while in Section 6 the conclusion and some possible future developments, based on the use of the blockchain technology, are reported.

\section{Literature review}

\subsection{Food traceability: General aspects}

In recent years, the number of studies about food traceability has considerably grown [3], especially because many problems of hygienic nature have seriously endangered the end customers health, who have unfortunately consumed contaminated foods. The occurrence of several food scandals has made consumers more demanding and careful; some notorious cases were: the mad cow disease which spread from Great Britain [4], the problem of dioxins in poultry in Belgium [5], the milk adulteration with melamine in China [6].

Food traceability is a very debated research topic. Multiple views and opinions are present in the literature. Olsen and Borit [7] analyse 101 scientific papers, with the aim to provide a definition of the term "traceability", that is: "the ability to access any or all information relating to that which is under consideration, throughout its entire life cycle, by means of recorded identifications". A good traceability system should be able to perform efficiently two fundamental operations: track and trace. Tracking means being able to follow, from a documentary point of view, a product from upstream to downstream along the supply chain; while tracing is the reverse process, which reconstructs the history of a product, using the information stored at each step of the supply chain [8]. According to McEntire et al. [9], 4 main features describe the level of traceability in a food supply chain (FSC):

- Breadth: the amount of information recorded by the traceability system;

- Depth: how far, upstream and downstream in the FSC, the traceability system can correctly track;

- Precision: the degree of assurance, with which the traceability system can locate product's movement;

- Access: the speed, with which the stored information can be transmitted to supply chain actors; the speed, with which the requested information can be disseminated to public health officials in case of food emergency;

The use of a traceability system is essential for today's food companies for various reasons, such as: compliance with regulations, attestation of product origin and identity, fraud prevention, and especially possibility of effectively addressing any sanitary outbreak [1]. In the latter case, the number of recalled products can be minimized, with consequent economic and logistics benefits [10].

It is quite difficult to determine a unique traceability framework, suitable for all contexts, since 
traceability is an interdisciplinary research field [11]. In the literature, there are several proposals with different aims. Bougdira et al. [12] develop a conceptual and general-purpose framework, which can guide a user through the development and deployment of a traceability system. They use an ontology, which represents the knowledge base for supporting traceability data management. Sanchez et al. [13] propose a general theoretical framework, based on cyber-physical systems, to support the development of traceability solutions in small manufacturing companies. It allows real-time traceability and process monitoring through a flexible and open architecture. The main advantages of such a modelare: reduction in the number of inefficiencies and reaction time in the event of a warning. Starting from regulatory aspects, Regattieri et al. [14] define a general framework for food traceability, based on 4 main pillars: product identification (e.g., volume, weight, perishability), data to trace (e.g., typology, data storage requirements), product routing (e.g., movement systems, storage systems, manual or automatic operations), traceability's tools (e.g., number of data readings or writings, data accuracy or reliability). They apply their model to the Parmigiano Reggiano supply chain with very good results for both manufacturers and consumers. Storoy et al. [15] present the TraceFood Framework, which contains: a set of recommendations for "Good Traceability Practice", a generic standard for electronic information exchange (i.e, TraceCore XML), some sector-specific ontologies, common principles for unique identification of food items. Pizzuti and Mirabelli [16] develop the Global Track \& Trace System (GTTS) for supporting the different users of a food supply chain in the traceability management. GTTS is very general and based on the following main steps: supply chain analysis, supply chain modelling, data analysis and modelling, system design and development. As properly demonstrated, it can be effectively applied in many real-life situations. Many other conceptual or practical frameworks for food traceability exist [17], [18], [19].

Practically, food traceability can be implemented by product labelling. A very common and cheap way is to use a sticker, on which a barcode, 2D code, or QR Code is printed. An alternative is represented by the use of an RFID tag, which has the advantage of easy readability, even at a distance of a few meters. These methods are widely used and recognized, but they can have some reliability problems: a sticker or an RFID tag can in fact be easily damaged and become ineffective. Therefore, a recent research branch concerns the use of direct product marking [20], which is a process used to mark permanently the main product information. In this context, some possibilities are: ink jet printing [21], and dot peen marking, whose reliability is discussed in [22].

\subsection{Food traceability: A regulatory overview in Europe}

Among all the laws promulgated over the years, the Regulation (EC) No. 178/2002 certainly represents a reference point for all the food operators in Europe. In fact, it lays down the general principles of food law, establishing the European Food Safety Authority. In particular, the food business operators are obliged to store information both on their direct suppliers and customers: for example, goods purchased or sold and their relative quantity, actors involved in transactions. The Regulation (EU) No. 1169/2011 is on the provision of food information to consumers. In particular, Article 9 establishes the information that must obligatorily be placed on the label, including: name of the food, list of ingredients, quantity of certain ingredients or categories of ingredients, date of minimum durability or the "use by" date, any special storage conditions and/or conditions of use. It is clear that this information is retrievable, reliable and complete only if an effective traceability system is implemented along the various steps of the agrifood chain. In this context, the lot definition is one of the fundamental aspects. The Directive 2011/91/ UE defines the term lot as "a batch of sales unit of foodstuff produced, manufactured or packaged under practically same conditions”. For more detailed information on the general regulations on food traceability in Europe and in the world, the reader is referred to the comprehensive research work carried out by Charlebois et al.[23].

\subsection{Traceability and olive oil supply chain}

Nowadays, traceability systems are implemented and diffused to guarantee the quality and safety of various types of food products: from fish to meat, from milk to wine, to fruit and vegetables. In this paper, we focus on the study of traceability systems about extra-virgin olive oil. The International Olive Council has established a classification for olive oil, based on the extraction procedure used: extra-virgin, virgin, refined, pomace. Extra-virgin olive oil is considered the one with the highest quality due to its organoleptic properties and its extremely beneficial ef- 
fects on human health. It should be noted that extra virgin olive oils may have quite different characteristics, considering that their quality depends on many factors, such as cultivar and environmental conditions of plant growth [24]. Below, we refer to the particular laws in the olive oil supply chain, whose knowledge is essential to design an adequate traceability system. The Commission Regulation (EEC) No. 2568/91 (and subsequent amendments) classifies olive oil on the basis of physical-chemical and organoleptic characteristics. More specifically, by using some important parameters, eight types of olive oils can be defined, including extra-virgin olive oil, which must have a free acidity (\% oleic acid) of no more than $0.8 \%$ and be obtained by extraction using only mechanical methods. The Regulation (EU) No. 29/2012 sets the marketing standards for olive oil: oil has to be presented to final consumers in packaging with a capacity of not more than 5 litres and the opening system can no longer be sealed after the first time it is opened. About labelling, the standard establishes a precise expression to be used according to the category of oil produced: for example, for extra-virgin olive oil the expression to be reported is: "superior category olive oil obtained directly from olives and solely by mechanical means". The EU therefore establishes important regulations regarding olive oil. In many other non-European countries, due to the limited (or even absent) production of this product, there are often no specific laws, but simply general regulations on food traceability. In this regard, it should be noted that according to the latest report of the International Olive Council, world consumption of olive oil has exceeded 3 million tons in the $2017 / 2018$ olive season [25]. Italy is historically among the 3 main world producers of olive oil together with Spain and Greece.

The main models currently used and, in some cases implemented, to ensure the traceability of olive oil are summarized below. It should be noted that we are referring to the concept of traceability from a purely documentary point of view: "documented proof of identity of a product and the responsibilities involved in the production chain from the field to the consumer table" [26]. Giametta and Sciarrone[27] propose a traceability system for olive oil. They identify the boundaries of the system (e.g., involved actors and material flows) through a flow chart and define a "dynamic lot" that depends on six main variables. The result of the defined system is a label based on the use of barcode that provides quickly and immediately the information about the origin of the product. Abenavoli et al. [28] propose a web application based on a cloud platform and centralize the information about the supply chain, from the agricultural field to the bottle. This system improves collaboration between different employees involved because they can be informed in real-time about any delays or problems within the chain through a smartphone application, synchronized with a cloud system. At the same time, even a consumer can easily retrieve all product information by downloading a consumer-oriented application. Papaefthimiou et al. [29] propose a framework, called OLEA, for monitoring the phases of the olive oil production chain. The system is equipped with a database that acquires information both from the NFC tags, located in the cultivation and warehouse areas, and from the sensors installed in the production department. The database can be queried using a web interface or a specific smartphone application.

Although there are many contributions in the literature regarding food traceability, the studies dedicated specifically to olive oil traceability, from a documentary point of view, are still few. To the best of our knowledge, this is the first paper that proposes the use of document traceability together with DNA analysis in the context of olive oil, in order to unambiguously attest that the produced oil is: extra- virgin, organic and Made in Italy. Furthermore, the proposed framework provides precise information about the cultivar, the test panel parameters and the activities carried out by the various actors in the supply chain. The database used in the proposed framework is relational and is fully in contrast with the non-relational one used by Abenavoli et al. [28]. These latter authors, while also proposing an application for smartphones for the traceability of olive oil, do not focus their attention on the analysis of the molecular footprint, which instead is, in this paper, the key factor that increases the perceived value of the product by the final consumer, fights unfair competition and avoids any attempt at counterfeiting.

\section{Problem description and analysis}

The object of the case study is a consortium of farmers located in Calabria (Consorziodelle Terre Nuove da Sibari, CTNS), who wish to increase the sales of their product to the final consumer, through the enhancement of its health content and implementation of a traceability system. Extra-virgin olive oil is today one of the most valuable products for the Calabrian territory. The consortium consists of 7 farms and an oil mill. The olive groves are located 
entirely in the province of Cosenza. There are 161 plots of land for a total of 136 hectares. The cultivation is organic and the cultivar is Tondina. The starting point of the case study is a supply chain characterized by significant problems from a documentary point of view. The various actors, due to some habits that have been handed down over the years, do not store all the data necessary to implement an effective and efficient system for tracking and tracing. In Figure 1 , the olive oil supply chain, concerning the case study, is represented.

The olive grower cultivates and harvests olives. The olives, through the transporters (one for each olive grower), are carried to the oil mill where the transformation into oil takes place. The operations carried out in the mill are: washing, milling, mixing, extraction and separation. The produced oil is sold to wholesalers and/or retailers, who deal with the marketing of the product and do not belong to the consortium. Moreover, at present only a small part of the production is destined for direct sale to final consumers. In terms of traceability, the main problem is the almost exclusive use of paper for storing information. At the moment, only a negligible percentage of information is in fact stored in parallel also in digital format. Another problem is represented by the quality of information: each actor tends to trace only and only what is legally required to record. Under a documentary point of view, the integration between the actors of the consortium is very scarce and this does not allow to be informed in real-time about what is happening along the supply chain or to quickly trace a lot in case offood emergency. Observe that currently the part of the supply chain which is locat- ed downstream from the oil mill, does not belong to the consortium and this represents a significant limit, since the oil is sold in tanks to wholesalers or retailers and many information is lost about any mixing that precedes the bottling phase.

Over the years, the farmers of the consortium have realized that the product, despite being excellent, is not sufficiently protected and valued. In fact, final consumer often prefers to buy the olive oils produced by the competitors as he/she is unable to perceive the quality of the extra-virgin olive oil produced by the consortium. The main goal is therefore to increase the perceived value by placing on each bottle an intelligent label equipped with a QR Code. It allows the final consumer to verify the truthfulness of the information on the label and justify the price of the product. The framework behind the QR Code is widely described in Section 4 .

\section{Proposed framework}

The proposed platform framework is based on web and mobile technologies. More specifically, it is a Relational Database Management System (RDBMS) platform, built using MySQL Workbench. All the stakeholders involved in the olive-oil supply chain can access to it at any time even with different access rights (i.e., olive growers, transporters, olive mill managers, who are consortium's stakeholders, as well as supervisory authorities, laboratory manager and final consumers). The framework architecture is depicted in Figure 2.

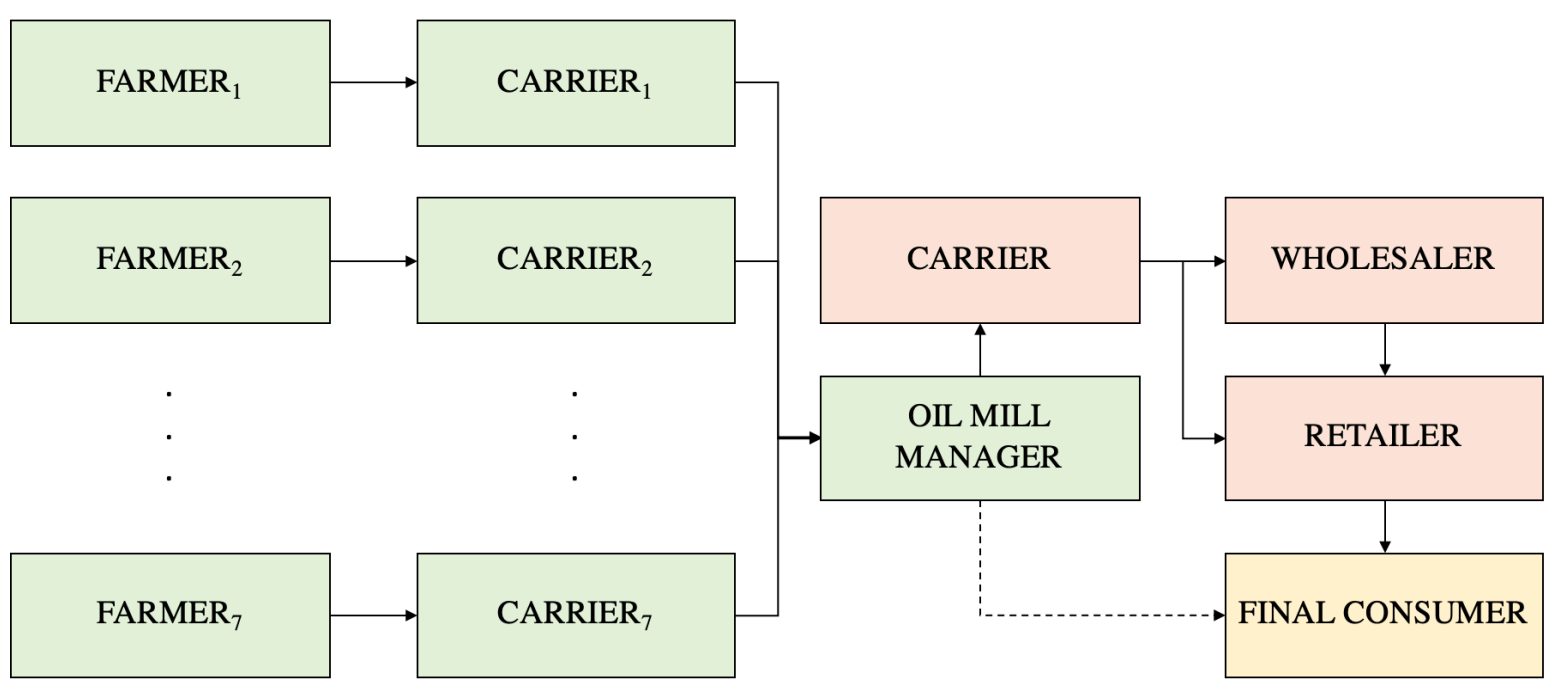

Figure 1. Olive oil supply chain of the case study 


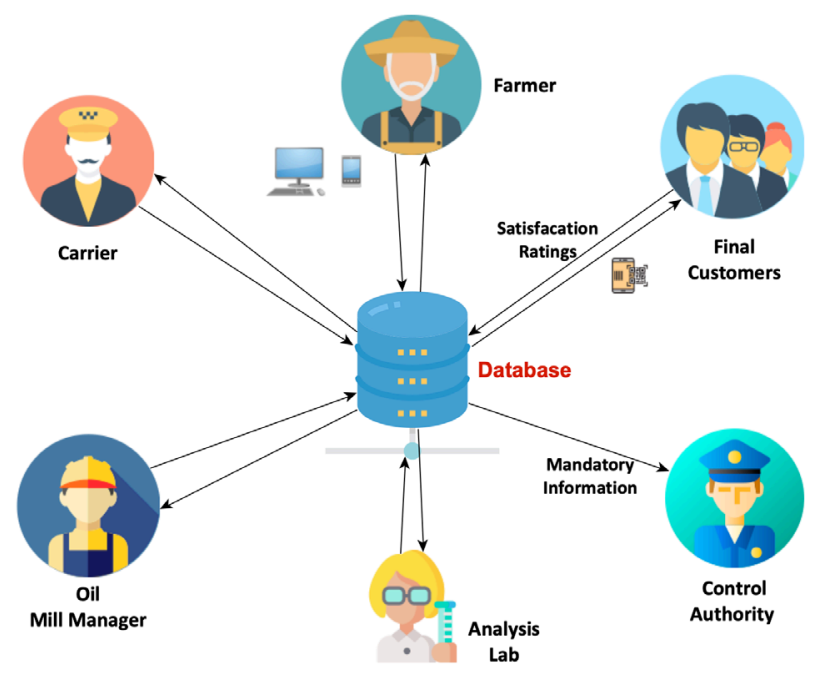

Figure 2. Proposed framework architecture

The main activities carried out on the tracking and traceability system by each stakeholder are specified below:

- Olive grower: each olive grower, through its manager, inserts information about agricultural production. $\mathrm{He} /$ she has to update in real time various registers: purchase register, cultivation register, harvest register, register of olive transfer to the mill;

- Carrier: each carrier inserts the information related to transported olives or oil and reported in the transport document;

- Oil mill manager: inserts information related to olives storage, processing of olives, oil storage and oil packaging. As far as storage is concerned, each bin and each tank must be uniquely identified. For that concerning the different process phases, it is necessary to keep track of the most significant process parameters (e.g., duration of the mixing process, decanter temperature);

- Control authority: has only read-only mode access to the system for periodic checks required by current legislation and appropriate checks that allow to trace the origin of any type of lot in case of food emergency;

- Analysis laboratory: the Research Centre for Olive Growing and Olive Product Industry (CREA-OLI) is currently partner of the consortium and it is a new actor, not mentioned in Section 3 as it was not present in the supply chain.
Its main contribution consists on verifying and documenting declared properties and characteristics of the final product through specific sample analyses. The laboratory performs chemical-physical analyses (e.g., acidity, peroxides, FT-NIR, DNA fingerprint), organoleptic evaluation by a test panel, and reports the results in the system;

- Final consumer: accesses to some system information by a QR Code placed on the product label. This information, which can influence his/her propensity to purchase, is related to the geographical origin of olive trees, olive cultivars, organoleptic characteristics of oil, type of cultivation (e.g., organic or traditional), processes which has undergone for each phase of the supply chain. Furthermore, the consumer himself/herself can enter information into the system by expressing opinion/ appreciation by commenting on the product or by judging it (by a rank from 1 to 5 ).

Figure 3 illustrates the main registers of the system that each actor of the supply chain must update. The figure highlights only the most representative information recorded in the database.

The developed tracking and tracing system includes the development of a web application by Django. It is a web framework with an open-source license, written in Python programming language. Databases and web applications can be hosted with relatively low costs through Amazon Simple Storage Service (Amazon S3). It is an object storage service that has high performance in terms of scalability and 
data availability. An annual cost of around 1000 euros is estimated considering that there are only variable costs and no fixed costs. These variable costs mainly depend on the amount of stored data and on the number of requests made for archiving. Flutter, which is an open-source framework offered by Google, is chosen to create the ODIN smartphone application, available for both iOS and Android. In this way, stakeholders can exploit the system in a simple manner, by a smartphone application or by connecting to the website.

Figure 4 reports the process in the supply chain that allows creating the QR Code. It summarizes information related to olive grower, transporter, oil mill manager, and analysis laboratory. The QR code is on the product label and a final consumer can scan it by his/her smartphone.

Figures 5-6 show some screenshots that a final consumer sees when he/she uses ODIN application. The two screenshots of Figure 5 are introductory and report the main information about the consortium and a simple guide about the correct use of the QR Code, respectively. The first screenshot of Figure 6 shows detailed information about the olive harvesting and delivery to oil mill (e.g., date and location). The results of the analysis carried out by the laboratory CREA-OLI are instead summarized in the second screenshot. In particular, it certifies that oil is extra-virgin, organic and 100\% Made in Italy. Finally, consumer can retrieve the relative documentation released by the laboratory and can display the graphs of the results of genetic analysis by clicking a button.

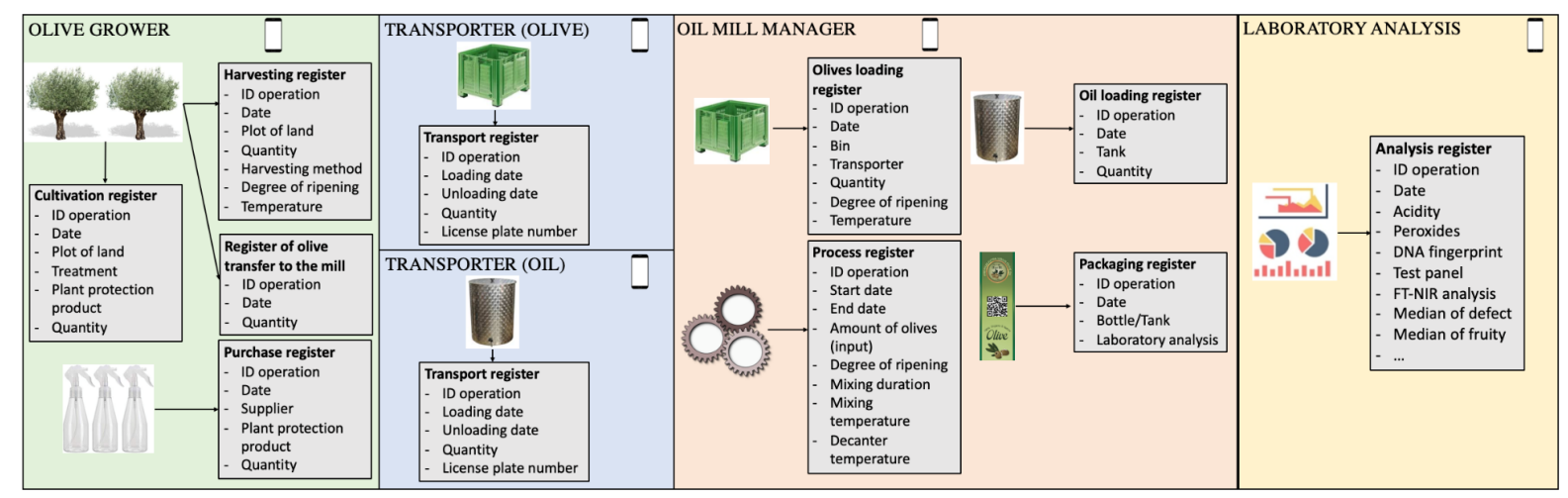

Figure 3. Main information in the database

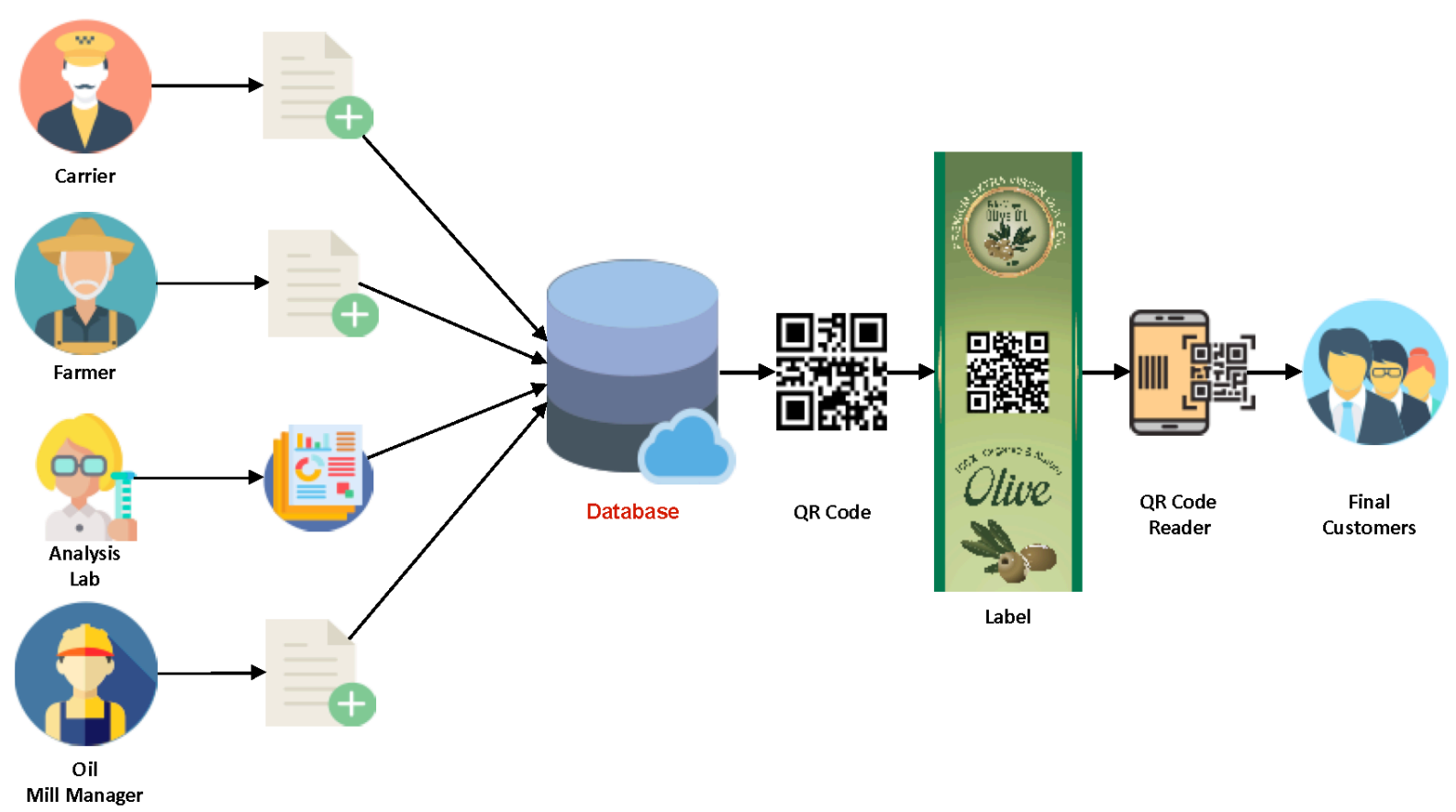

Figure 4. Creation and reading of the QR Code 

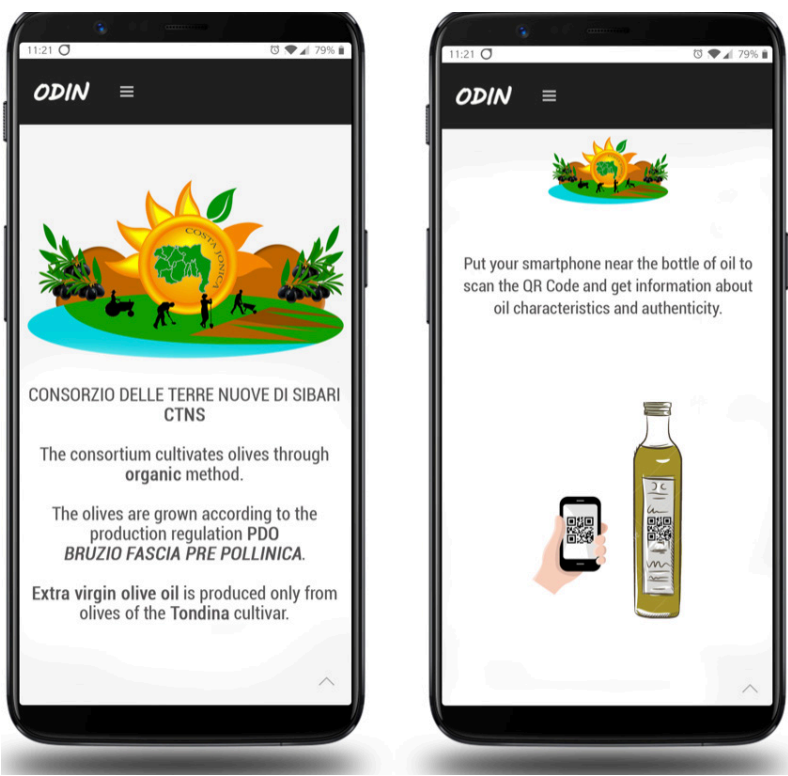

Figure 5. Introductory information in ODIN application

\section{Preliminary/expected results}

The project is nearing completion; therefore, it has not yet been possible to test the proposed framework on multiple olive growing campaigns. However, some preliminary considerations can be made, both from quantitative and qualitative point of view.

\subsection{Quantitative results}

The consortium produces on average 95 tons of olive oil per year, taking into account that the olive fields are characterized by alternating yearly yield. Before the implementation of the project, $45 \%$ of the olive oil produced was destined for wholesalers, while the residual part (55\%) was for retailers. The revenue was around 450000 Euro/year.

The successful progress of the research project has strengthened, among the consortium members, the awareness of producing high-quality extra-virgin olive oil, and the belief of being able to demonstrate to the final consumer the area of origin and the truthfulness of the data shown on the label. As a result, a new commercial strategy has been implemented. The percentage of olive oil sold to retailers has grown from $55 \%$ to $65 \%$. The use of the smart label has allowed a price increase for both wholesalers and retailers, resulting in an overall increase in revenue of $19 \%$. Considering the higher incidence of packaging and distribution activities, costs have grown by about $25 \%$ overall. However, the increase in profit is $9.1 \%$, given the significant growth in revenues and the different product placement on the various distribution channels. Both before and after the project,

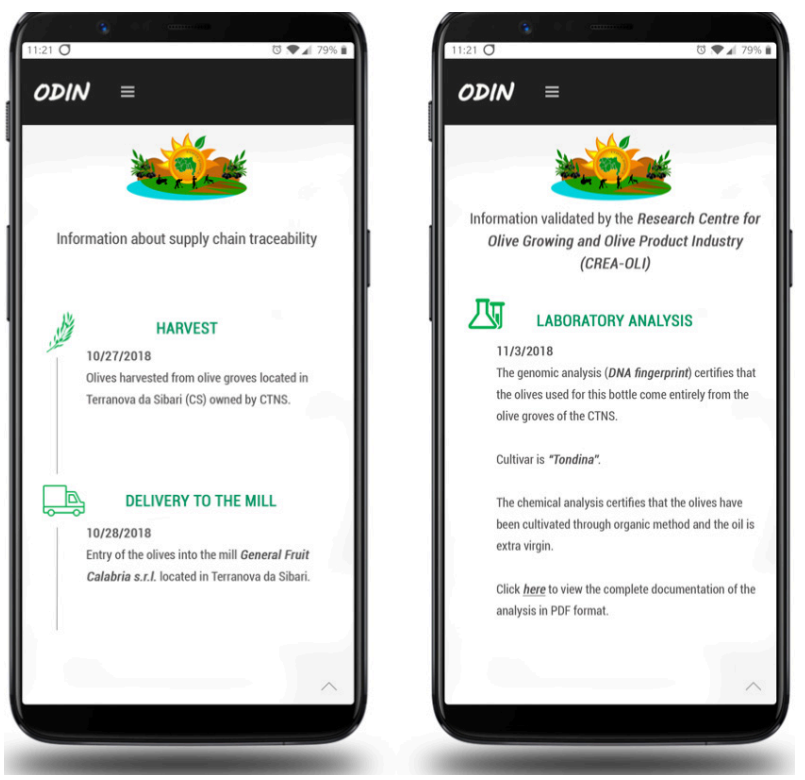

Figure 6. Supply chain information retrieval by ODIN application

the quantity of olive oil, sold directly to the final consumer, can be considered negligible.

\subsection{Qualitative results}

Many tests were performed by populating the database with data about the 2018-2019 and 2019-2020 seasons with good results both in terms of simplicity of use and scalability. The advantages deriving from the use of the proposed framework are listed below:

- $\quad$ the QR Code label gives greater value to the product, allowing the consumer to verify what is reported on the label and persuading him/her to pay even a higher price compared to "similar" products, thanks to the transparency of the entire supply chain that protects him/her from fraud;

- decrease in recall costs, in case of contaminated bottles. Identification of "defective" lots is made easier thanks to a more orderly storage of information along the supply chain;

- Made in Italy enhancement;

- More efficient organization of the processes along the supply chain: the implementation of a traceability system like the one described above can be seen as the trigger, able to redefine the processes along the supply chain, improving them. For example, the manager of the oil mill, having real-time information about the olive harvesting activities by the farmers, can 
better organize his/her activities; the scheduling of the different production cycles is made more efficient, based on forecasts of arrival of the transporters. Similarly, the analyses carried out by the laboratory can quickly report any anomalies in the oil and correct promptly certain activities before their effects are reflected downstream, with significant economic consequences.

- $\quad$ The proposed framework, in addition to digitizing and optimizing document traceability, implements further technology to ensure the truthfulness of product information. In particular, genetic analysis of DNA fingerprints reassure the consumer about the geographical origin and variety of the oil.

\section{Conclusion and future developments}

In this paper, a framework for tracking and tracing extra-virgin olive oil, referring to a supply chain located in Southern Italy, is proposed. Considering the strong similarity among various olive oil chains both at Italian and foreign level, the model can represent a point of reference for all those actors who, starting from a condition of fragmentation in the storing of information, want to make more efficient the information flow along the chain and be able to effectively track and trace the operations undergone by product.

Future developments may include the use of blockchain technology, which refers to the evolution of algorithms and IT infrastructures, introduced for the first time in 2008 in the financial field by Satoshi Nakamoto, to monitor and control monetary transactions [30]. Today, this technology is of considerable interest for its multiple applications, especially in supply chain and logistics [31].

In Italy, which has always been a leader in the food sector, a large number of PDO products are experimenting with the use of the blockchain. Companies and institutions of primary importance such as Barilla, IBM and Coldiretti, as well as a large group of innovative start-ups, are investing in experimentation and pilot projects to develop the technology and adapt it to business and supply chain contexts [32]. Even from the regulatory point of view, Italy can boast the primacy of having approved the first rules that recognize smart contracts and legally equate them to traditional contracts, through the Decree-Law No. 35 in 2018.

The blockchain technology appears very promising, especially for traceability purposes in agricultural supply chains [33]. Moreover, it can be integrated with the Internet of Things [34], whose potentials in the food supply chain are really significant [35]. The main advantages related to the use of the blockchain with respect to the traceability methods currently used concern: the absence of a third party which is responsible for controlling the logistics chain [36]; greater transparency of data and information, immediate indication of the origin of the products, less traceability times in the event of a food crisis [37]; greater efficiency in the logistics chain by reducing delivery times; drastic reduction of commercial intermediation and consequent control of sales and purchase prices; speed and security in payments [38]; greater capacity of the end customer in controlling the type and characteristics of the product purchased (organic products, products from Vegan supply chains, etc.) [39], greater economic security for primary producers by being able to plan agricultural and crop activities according to stipulated supply contracts before the start of the activities. However, although the blockchain technology is extremely promising and has several advantages, its development is at an early stage, then much effort is still necessary for reaching the maturation phase [31].

\section{Funding}

This research was partly supported by the project: Olio extra vergined'oliva Digital Id Management (ODIN) - CUPJ88C17000170006 (website: http:// www.odinproject.it).

\section{References}

[1] F. Dabbene, P. Gay, C. Tortia, "Traceability issues in food supply chain management: A review," Biosyst. Eng., vol. 120, pp. 65-80, April 2014, doi: https://doi.org/10.1016/j. biosystemseng.2013.09.006.

[2] Coop Italia. "Rapporto Coop 2018 - English Version," [Online]. Available: http://www.italiani.coop/ wp-content/uploads/2019/02/rapporto-coop-2018-eng-webrid.pdf. [Accessed: 27-Aug-2019].

[3] P. Olsen, M. Borit, "The components of a food traceability system," Trends Food Sci. Tech., vol. 77, pp. 143-149, July 2018, doi: https://doi.org/10.1016/j.tifs.2018.05.004.

[4] J. M. E. Pennings, B. Wansink, M. T. G. Meulenberg, “A note on modeling consumer reactions to a crisis: The case of the mad cow disease," Int. J. Res. Mark., vol. 19, 
no. 1, pp. 91-100, March 2002, doi: https://doi.org/10.1016/ S0167-8116(02)00050-2.

[5] W. Verbeke, "Beliefs, attitude and behaviour towards fresh meat revisited after the Belgian dioxin crisis," Food Qual. Prefer., vol. 12, no. 8, pp. 489-498, Dec. 2001, doi: https:// doi.org/10.1016/S0950-3293(01)00042-8.

[6] X. Pei, A. Tandon, A. Alldrick, L. Giorgi, W. Huang, R. Yang, "The China melamine milk scandal and its implications for food safety regulation," Food Policy, vol. 36, no. 3, pp. 412-420, June 2001, doi: https://doi. org/10.1016/j.foodpol.2011.03.008.

[7] P. Olsen and M. Borit, "How to define traceability," Trends Food. Sci. Tech., vol. 29, no. 2, pp. 142-150, Feb. 2013, doi: https://doi.org/10.1016/j.tifs.2012.10.003.

[8] T. Pizzuti, G. Mirabelli, M. A. Sanz-Bobi, and F. Goméz-Gonzaléz, "Food Track \& Trace ontology for helping the food traceability control,” J. Food Eng., vol. 120, no. 1, pp. 17-30, Jan. 2014, doi: https://doi.org/10.1016/j. jfoodeng.2013.07.017.

[9] J. C. McEntire, S. Arens, M. Bernstein, B. Bugusu, F. F. Busta, M. Cole, A. Davis, W. Fisher, S. Geisert, H. Jensen, B. Kenah, B. Lloyd, C. Mejia, B. Miller, R. Mills, R. Newsome, K. Osho, G. Prince, S. Scholl, D. Sutton, B. Welt, S. Ohlhorst, "Traceability (Product Tracing) in Food Systems: An IFT Report Submitted to the FDA, Volume 1: Technical Aspects and Recommendations," Compr. Rev. Food Sci. F., vol. 9, no. 1, pp. 92-158, Jan. 2010, doi: 10.1111/j.1541-4337.2009.00097.x.

[10] H. Dai, M. M. Tseng, P. H. Zipkin, "Design of traceability systems for product recall,” Int. J. Prod. Res., vol. 53, no. 2, pp. 511-531, 2015, doi: https://doi.org/10.1080/00207543.2 014.955922.

[11] K. M. Karlsen, B. Dreyer, P. Olsen, E. O. Elvevoll, "Literature Review: Does a common theoretical framework to implement food traceability exist?," Food Control., vol. 32, no. 2, pp. 409-417, Aug. 2013, doi: https://doi.org/10.1016/j.foodcont.2012.12.011.

[12] A. Bougdira, A. Ahaitouf, I. Akharraz, "Conceptual frame work for general traceability solution: description and bases," J. Model. Manag., in press, 2019, doi: https://doi.org/10.1108/JM2-12-2018-0207.

[13] B. B. Sanchez, R. Alcarria, D. Martin, T. Robles, "TF4SM: A Framework for Developing Traceability Solutions in Small Manufacturing Companies," Sensors, vol. 15, no. 11, pp. 29478-29510, Nov. 2015, doi: https://doi.org/10.3390/ s151129478.

[14] A. Regattieri, M. Gamberi, R. Manzini, "Traceability of food products: General framework and experimental evi dence,” J. Food Eng., vol. 81, no. 2, pp. 347-356, July 2007, doi: https://doi.org/10.1016/j.jfoodeng.2006.10.032.

[15] J. Storoy, M. Thakur, P. Olsen, "The TraceFood Framework - Principles and guidelines for implementing traceability in food value chains," J. Food Eng., vol. 115, no. 1, pp. 41-48, March 2013, doi: https://doi.org/10.1016/j.jfood eng.2012.09.018.

[16] T. Pizzuti, G. Mirabelli, "The Global Track\&Trace System for food: General framework and functioning principles," J. Food Eng., vol. 159, pp. 16-35, Aug. 2015, doi: https://doi.org/10.1016/j.jfoodeng.2015.03.001.

[17] C. Shanahan, B. Kernan, G. Ayalew, K. McDonnell, F. Butler, S. Ward, "A framework for beef traceability from farm to slaughter using global standards: An Irish perspective," Comput. Electron. Agr., vol. 66, no. 1, pp. 62-69, Apr. 2009, doi: https://doi.org/10.1016/j.compag.2008.12.002.

[18] M. Thakur, C.-F. Sorensen, F. O. Bjornson, E. Foras, C. R. Hurburg, "Managing food traceability information using EPCIS framework," J. Food Eng., vol. 103, no. 4, pp. 417-433, April 2011, doi: https://doi.org/10.1016/j.jfoodeng.2010.11.012.
[19] M. Salampasis, D. Tetkonidis, E. P. Kalogianni, "TraceALL: a semantic web framework for food traceability systems,” J. Syst. Inf. Techn., vol. 14, no. 4, pp. 302-317, Nov. 2012, doi: https://doi.org/10.1108/13287261211279053.

[20] N. K. Vedel-Smith, T. A. Lenau, "Casting traceability with direct part marking using reconfigurable pin-type tooling based on paraffin-graphite actuators," J. Manuf. Syst., vol. 31, no. 2, pp. 113-120, Apr. 2012, doi: https://doi.org/10.1016/j.jmsy.2011.12.001.

[21] K. Liang, J. A. Thomasson, K.-M. Lee, M. Shen, Y. Ge, T. J. Herrman, "Printing data matrix code on food-grade tracers for grain traceability,” Biosyst. Eng., vol. 113, no. 4, pp. 395-401, Dec. 2012, doi: https://doi.org/10.1016/j.bio systemseng.2012.09.012.

[22] D. Dragicevic, S. Tegeltija, G. Ostojic, S. Stankovski, M. Lazarevic, "Reliability of Dot Peen Marking in Product Traceability,” Int. J. Ind. Eng. Manag., vol. 8, no. 2, pp. 7176, June 2017.

[23] S. Charlebois, B. Sterling, S. Haratifar, and S. K. Naing, "Comparison of Global Food Traceability Regulations and Requirements," Compr. Rev. Food Sci. F., vol. 13, no. 5, pp. 1104-1123, Sep. 2014, doi: https://doi. org/10.1111/1541-4337.12101.

[24] C. Consolandi, L. Palmieri, M. Severgnini, E. Maestri, N. Marmiroli, C. Agrimonti, L. Baldoni, P. Donini, G. De Bellis, B. Castiglioni, "A procedure for olive oil traceability and authenticity: DNA extraction, multiplex PCR and LDR-universal array analysis," Eur. Food Res. Technol., vol. 227, no. 5, pp. 1429-1438, Sep. 2008, doi: https://doi. org/10.1007/s00217-008-0863-5.

[25] International Olive Council. "World Olive Oil Figures, Consumption - English Version." [Online]. Available: https://www.internationaloliveoil.org/wp-content/uploads/ 2020/01/HO-W901-29-11-2019-C.pdf. [Accessed: 11-Feb2020].

[26] B. Zanoni, "Extra-virgin olive oil traceability," in The Extra-Virgin Olive Oil Handbook, C. Peri, John Wiley \& Sons, Chichester, UK, 2014, pp. 245-250, doi: 10.1002/9781118460412.

[27] F. Giametta and G. Sciarrone, "An integrated technological traceability model in the olive growing production chain," J. Agr. Eng., vol. 39, no. 4, pp. 19-26, Dec. 2008, doi: https://doi.org/10.4081/jae.2008.4.19.

[28] L. M. Abenavoli, F. Cuzzupoli, V. Chiaravalloti, and A.R. Proto, "Traceability system of olive oil: a case study based on the performance of a new software cloud," Agronomy Research, vol. 14, no. 4, pp. 1247-1256, 2016.

[29] D. Papaefthimiou, A. Ventouris, I.-M. Tabakis, S. Valsamidis, I. Kazanidis, S. Kontogiannis, "OLEA frame work for non refined olive oil traceability and quality assurance," CEUR Workshop Proceedings., vol. 2030, pp. 91-103, 2017.

[30] S. Nakamoto, "Bitcoin: A Peer-to-Peer Electronic Cash System,” 2008, link: https://bitcoin.org/bitcoin.pdf.

[31] V. Astarita, V. P. Giofrè, G. Mirabelli, V. Solina, "A Review of Blockchain-Based Systems in Transportation," Information, vol. 11, no. 1, pp. 1-24, Jan. 2020, doi: https://doi.org/10.3390/info11010021.

[32] F. Antonucci, S. Figorilli, C. Costa, F. Pallottino, L. Raso, P. Menesatti, "A review on blockchain applications in the agri-food sector,” J. Sci. Food Agric., vol. 99, no. 14, pp. 6129 -6138, Nov. 2019, doi: https://doi.org/10.1002/jsfa.9912.

[33] O. Bermeo-Almeida, M. Cardenas-Rodriguez, T. Samaniego-Cobo, E. Ferruzola-Gomez, R. CabezasCabezas, W. Bazan-Vera, "Blockchain in agriculture: A systematic literature review," Comm. Comp. Inf. Sci., vol. 883, pp. 44-56, 2018, doi: https://doi.org/10.1007/9783-030-00940-3_4.

[34] K. Christidis, M. Devetsikiotis, "Blockchains and Smart 
Contracts for the Internet of Things," IEEE Access, vol. 4, pp. 2292-2303, 2016, doi: 10.1109/ACCESS.2016.2566339.

[35] I. Beker, M. Delic, S. Milisavljevic, D. Gosnik, G. Ostojic,

S. Stankovski, "Can IoT be Used to Mitigate Food Supply Chain Risk?,” Int. J. Ind. Eng. Manag., vol. 7, no. 1, pp. 4348, March 2016.

[36] T. Ahram, A. Sargolzaei, S. Sargolzaei, J. Daniels, B. Amaba, "Blockchain technologyinnovations," in Proceedings of the 2017 IEEE Technology and Engineering Management Society Conference (TEMSCON), Santa Clara, USA, 2017, pp. 137-141.

[37] F. Tian, "A Supply Chain Traceability System for Food Safety Based on HACCP, Blockchain \& Internet of Things," in Proceedings of the 14th International Conference on Services Systems and Services Management, Dalian, China, 2017, pp. 1-6, doi: 10.1109/ICSSSM.2017.7996119.

[38] D. Macrinici, C. Cartofeanu, S. Gao, "Smart contract applications within blockchain technology: A systematic mapping study," Telemat. Inform., vol. 35, no. 8, pp. 2337 2354, Dec. 2018, doi: https://doi.org/10.1016/j. tele.2018.10.004.

[39] Q. Lu, X. Xu, "Adaptable Blockchain-Based Systems: A Case Study for Product Traceability," IEEE Softw., vol. 34, no. 6, pp. 21-27, Nov. 2017, doi: 10.1109/MS.2017.4121227. 